\title{
Adolescentes e jovens em situação de risco psicossocial: redes de apoio social e fatores pessoais de proteção
}

\author{
Deise Matos do Amparo \\ Afonso Celso Tanus Galvão \\ Universidade Católica de Brasilia \\ Paola Biasoli Alves \\ Universidade Federal do Mato Grosso \\ Katia Tarouquella Brasil \\ Universidade Católica de Brasília \\ Silvia Helena Koller \\ Universidade Federal do Rio Grande do Sul
}

\begin{abstract}
Resumo
Este estudo visou investigar fatores sociais e pessoais que possam servir como proteção a adolescentes e jovens em situação de risco social e pessoal. Os participantes foram 852 adolescentes e jovens, cursando o ensino médio em escolas públicas do Distrito Federal, com idade entre 13 e 27 anos, que responderam a um questionário com 109 questões sobre risco e proteção em seu desenvolvimento. Os resultados enfocam as redes de proteção (família, escola, amigos) e os fatores pessoais (auto-estima, religiosidade-espiritualidade). Os adolescentes e jovens apresentam processos de resiliência global (social, emocional e acadêmica), evidenciando a confiança em si mesmos e na rede composta por escola, família e amigos. A análise dos dados enfatiza a compreensão contextual da adolescência e juventude no Brasil e a necessidade de implementação de políticas públicas para essas populações que permitam o exercício e a significação de suas experiências positivas e protetivas.
\end{abstract}

Palavras-chave: adolescência; proteção; redes sociais

\begin{abstract}
Adolescence and youth at risk situation: social network and personal protective factors. This study aimed to investigate social and personal factors that can serve as protection to adolescents and youths in situation of social and personal risk. The participants were 852 adolescents and youths of public schools of the Federal District, aged 13 to 27 years, who answered a questionnaire with 109 items about risk and protection in their development. The results focused on the protection networks (family, school, friends) and the personal factors (self-esteem, religiosity-spirituality). The adolescents and youths presented processes of global resilience (social, emotional and academic), evidencing the trust in themselves and in the composed network by school, family and friends. The data analyses show the importance of understanding adolescence and youth as a contextual process in Brazil and the necessity of youth's public polices to exercise and to internalize positive and protective experiences.
\end{abstract}

Keywords: adolescence; protection; social network

$\mathrm{D}$ e acordo com a literatura psicológica nas dimensões bio-ecológica, da Psicologia Positiva e da Psicologia do Desenvolvimento, os processos de proteção têm como função básica interagir com o impacto de fatores de risco e proporcionar alternativas para resolução dos problemas vivenciados no cotidiano de risco psicossocial. Neste estudo investigaram-se os fatores sociais e pessoais de proteção de adolescentes e jovens do Distrito Federal, compreendendo a importância destes na diminuição do risco e também no estabelecimento da auto-estima, da auto-eficácia e do fortalecimento das relações de apoio em rede, que criam condições para reversão do stress (Branden, 1998; Rutter, 1987; Werner \& Smith, 1992). É relevante apresentar que os indicadores de risco, inicialmente presentes no estudo, são aspectos relativos ao Índice de Desenvolvimento Humano (IDH) $\mathrm{e}$ à renda familiar.

Este estudo descreve adolescentes e jovens das regiões administrativas do Distrito Federal (DF) e faz parte de uma 
pesquisa nacional, realizada em estados do Sul, Sudeste, Centro-Oeste e Nordeste do Brasil e que teve como objetivo traçar o perfil mais amplo dos adolescentes e jovens em situação de risco psicossocial nestas regiões. Investiga, ainda, aspectos relacionados às suas vivências de risco e de proteção no cotidiano, assim como identifica aspectos pertinentes à resiliência e à vulnerabilidade na vida destes brasileiros. Este recorte nos dados favorece a compreensão da temática no DF e, ainda, viabiliza a estruturação e implementação de estratégias regionais de intervenção e a valorização de aspectos saudáveis do desenvolvimento, uma vez que esta é a ênfase dos estudos e discussões sobre fatores pessoais de proteção e redes de apoio.

A primeira perspectiva teórica que fundamenta a pesquisa foi inicialmente proposta por Urie Bronfenbrenner ao longo das décadas de 70, 80 e 90 do século XX e permanece em construção, por meio de seus colaboradores, no século XXI, sendo denominada de Teoria dos Sistemas Ecológicos ou, mais recentemente, como Teoria Bioecológica do Desenvolvimento. Fundamenta-se, também, na Psicologia Positiva, estruturada a partir da década de 80 do século XX e em ampla construção nos dias atuais. Para ambas as teorias, o indivíduo humano desenvolve-se na integralidade entre pessoa-ambiente e, necessariamente, deve ter suas características pessoais e ambientais compreendidas através do paradigma da complexidade, explorando seu potencial de saúde, a ocorrência dos comportamentos em situação natural e a explicação dos fenômenos humanos de acordo com seus aspectos "ótimos", ou seja, de acordo com a valorização dos sentidos e significados favoráveis ao desenvolvimento atribuídos pelos próprios indivíduos (Bronfenbrenner, 1979/1996, 1989; Koller, 2004; Morais \& Koller, 2004; Narvaz \& Koller, 2004).

A Psicologia Positiva, enquanto concepção de ser humano e de mundo, em concordância com a Teoria dos Sistemas Ecológicos, valoriza a saúde e os fatores e processos que promovem o desenvolvimento psicológico humano. Essa teoria enfatiza um conjunto de condições apresentadas pelo indivíduo, que lhe permitem a vivência saudável junto ao meio social (Seligman \& Csikszentmihalyi, 2000). A Psicologia Positiva tem sido apresentada como um modelo que enfatiza a visão mais favorável, aberta e apreciativa dos potenciais, das motivações e das capacidades humanas. Dentro desse contexto, alguns fenômenos vêm sendo apontados como sistemas de construção saudável ao longo do desenvolvimento, em especial, a resiliência (Koller \& Lisboa, 2007).

A definição de resiliência teve sua origem nas ciências exatas, mais precisamente, na física e na engenharia, com o cientista inglês Thomas Young, ao buscar, por meio de experimentos, a relação entre a força aplicada num corpo e a deformação que esta produzia (Rutter, 1987, 1993). Sendo assim, a resiliência é entendida nessas áreas como a propriedade de um determinado corpo restituir o seu formato original após ser submetido a uma força externa. Um material de borracha, por exemplo, quando exposto à aplicação de uma força física, volta a sua forma inicial quando esta força é retirada. Já um material de argila, mesmo quando a força é retirada, mantém a marca da energia aplicada (Koller, 1999). Dessa forma, define-se resiliência como a capacidade que um ser humano, uma família, um grupo social, tem de se recuperar psicologicamente quando são submetidos a adversidades, violências, enfrentando-as, sendo transformados por elas, e no fim, superando-as (Pinheiro, 2004). O termo é compreendido por Rutter $(1987,1993)$ como uma união de processos sociais e psíquicos que permitem ao indivíduo ter um desenvolvimento sadio, mesmo que este esteja vivendo em um ambiente desfavorável. Já Grotberg (1995) a define como uma capacidade universal que possibilita a um grupo, pessoa ou comunidade se prevenir, minimizar ou, até mesmo, superar os efeitos nocivos das adversidades. Em síntese, a resiliência é entendida como a possibilidade de superação por meio da ressignificação do problema, isto é, lidar com as adversidades sem submeter-se às mesmas (Junqueira \& Deslandes, 2003).

De acordo com a literatura podem ser identificadas três dimensões de resiliência: acadêmica, social e emocional. Em cada uma destas dimensões há fatores e mecanismos de proteção. A resiliência acadêmica caracteriza-se pela construção do conteúdo acadêmico de forma saudável e funcional, podendo ser observada pelo bom desempenho escolar, pelo interesse da escola e do estudante em construir e implementar novas estratégias de ensino-aprendizagem e de resoluções de problemas relacionados à aprendizagem, além da formação continuada de seus funcionários. A resiliência social caracteriza-se pela construção saudável de aspectos interativos como amizades, aspectos morais pró-socias e competência social e pode ser identificada no bom relacionamento interpessoal, na capacidade de empatia e no senso de pertencimento dos indivíduos, por exemplo. Já a resiliência emocional caracteriza-se pelo sentimento de auto-eficácia, autonomia, auto-estima, confiança em suas potencialidades e o conhecimento de suas limitações, estando presente na resolução de situações de conflito íntimo ou social, como por exemplo, no término de um relacionamento, na perda de pessoas importantes, na situação de demissão de emprego, entre outras (Luthar, 1993).

Essas diferentes dimensões da resiliência remetem à definição de ambiente ecológico: estruturas que sustentam as atividades, os papéis e as relações interpessoais que cada indivíduo poderá estabelecer. Família, escola, grupo de pares, trabalho, lazer são ambientes nos quais o indivíduo se movimenta e se relaciona com outros, podendo estar vulnerável a situações adversas, exercitando, assim, sua capacidade de resiliência. Ainda, não há consenso quanto ao número de eventos de vida negativos necessários para afetar a capacidade de resiliência do indivíduo. Considerando que as experiências de vida negativas são inevitáveis para qualquer indivíduo, sobressai a questão dos níveis de exposição e dos limites individuais de cada um. Uma situação poderá ser enfrentada como perigo para um e apenas como um desafio para outro (Yunes, 2003; Yunes \& Szymanski, 2001).

Nesse sentido, ao se considerar fatores de risco, tais como: condições de pobreza e empobrecimento, rupturas na família, vivência de algum tipo de violência, deve-se levar em consideração a questão da resiliência, bem como dos fatores de proteção. Esses fatores interagem na relação dos indivíduos com o ambiente de risco tornando-os resilientes e auxiliando-os a desenvolverem sua adaptabilidade, segurança, autonomia e criatividade. De acordo com Werner (1993), além dos aspectos protetores decorrentes das relações parentais e da rede social 
de apoio, o sentimento de confiança que o indivíduo apresenta na superação dos obstáculos confirma a ênfase dos aspectos psicológicos e dos recursos internos, no esforço de lidar com as situações adversas. De Antoni e Koller (2004) confirmam esta idéia, ao declararem que a pessoa resiliente possui autoconfiança, acreditando que terá oportunidades na vida. Branden (1998) cita outro fator pessoal importante na superação dos problemas: a auto-estima.

De forma didática, Branden (1998) apresenta três tipos de fatores de proteção para o indivíduo: (1) fatores individuais, tais como auto-estima positiva, autocontrole, autonomia, características de temperamento afetuoso e flexível; (2) fatores familiares, como coesão, estabilidade, respeito mútuo, apoio/ suporte; e, (3) fatores relacionados ao apoio do meio ambiente, como bom relacionamento com amigos, professores ou pessoas significativas que assumam papel de referência segura à criança e a faça sentir querida e amada (Branden, 1998). A presença de um fator de proteção pode determinar o surgimento de outros fatores em algum outro momento. Portanto, compreender de que forma esses mediadores agem para atenuar os efeitos negativos do estresse ou do risco é tarefa tão complexa quanto determinar o que é fator de adversidade para cada ser humano (Pesce, Assis, Santos, \& Oliveira, 2005). Ainda, quatro são as principais funções são atribuídas aos processos de proteção: (1) reduzir o impacto dos riscos, fato que altera a exposição da pessoa à situação adversa; (2) reduzir as reações negativas em cadeia que seguem a exposição do indivíduo à situação de risco; (3) estabelecer e manter a auto-estima e auto-eficácia, por meio do estabelecimento de relações de apego seguras e o cumprimento de tarefas com sucesso; (4) criar oportunidades para reverter os efeitos do estresse (Pinheiro, 2004; Rutter, 1987).

Dentro deste contexto, os dados aqui apresentados são referentes à investigação dos mecanismos de proteção e à resiliência que os jovens de quatro regiões administrativas do Distrito Federal apresentam frente às situações desfavoráveis ao seu desenvolvimento.

\section{Método}

\section{Participantes}

Os participantes da pesquisa compõem um grupo de 852 indivíduos, entre adolescentes e jovens, cursando o ensino médio em escolas públicas das regiões administrativas de Planaltina, Brazlândia, Paranoá e Samambaia, do Distrito Federal, com idade entre 13 e 27 anos, sendo que $68,5 \%$ da amostra concentra-se na faixa etária de 15 a 17 anos (média de 16 anos, com desvio padrão de 1,58). A presença de uma faixa etária tão extensa justifica-se pela diversidade cronológica de adolescentes e jovens entre os três anos de ensino médio e, neste estudo, não houve critério de exclusão de participantes pela idade, referendando-se, somente, a série de escolarização. No que diz respeito ao gênero, $57,4 \%$ dos participantes são do sexo feminino, $41,5 \%$ do sexo masculino e $1,1 \%$ não se identificou. Quanto à renda familiar mensal, $35 \%$ dos participantes têm rendimentos entre um e dois salários mínimos; $22 \%$ entre mais de dois a três salários mínimos; enquanto que
$18,7 \%$ relatam renda superior a três salários mensais. Metade dos participantes $(52,4 \%)$ tem pais que são migrantes do interior de outros estados do Brasil.

\section{Instrumento e procedimentos}

Como os dados aqui apresentados foram retirados de uma amostra composta para estudo nacional, apresenta-se, a seguir, a composição geral do instrumento e as respectivas instruções de aplicação. Foi utilizado um questionário para levantamento de fatores de risco e proteção que consta de 109 questões de múltipla escolha em diferentes modelos (múltiplas alternativas, escalas Likert, entre outros), com questões elaboradas a partir de dados da literatura na área e instrumentos utilizados em pesquisas de cooperação nacional e internacional (consultas às referências no site www.ufrgs.br/ceprua), e investiga aspectos sobre a caracterização bio-sócio-demográfica dos participantes, assim como sobre as temáticas de educação, saúde (incluindo drogas e sexualidade), trabalho, violência, lazer, religiosidade, rede de apoio social, humor, auto-estima e auto-eficácia. O instrumento foi respondido individualmente em situação coletiva, em pequenos grupos nas salas de aula. Para este estudo foram utilizados os dados referentes às redes de apoio (família, amigos e a escola) e aos fatores de proteção pessoal (religiosidade-espiritualidade e auto-estima), definidos na literatura apresentada neste artigo como indicadores potenciais de processos resilientes.

A seleção da região para coleta dos dados foi realizada considerando as áreas do Distrito Federal com Índices de Desenvolvimento Humano mais baixos. Além deste dado, a renda familiar baixa, o índice de analfabetismo e a precariedade das condições de moradia foram considerados para a escolha das regiões em que seriam contatadas as escolas e, por conseguinte, caracterizada a amostra de adolescentes. Para a escolha das escolas utilizaram-se as informações sobre: localização (áreas com indicadores aparentes de pobreza, tais como concentração de barracos, saneamento básico inadequado), presença de jovens nas idades requeridas (de 13 a 27 anos) e nível sócio-econômico (baixo) da clientela atendida. O número de escolas participantes não foi previamente definido e, sim, o número de adolescentes, portanto, o número de escolas variou de uma a três em cada Região Administrativa, sendo que o critério foi a autorização para o preenchimento dos questionários pelos adolescentes Para coleta de dados, em um primeiro contato, os(as) pesquisadores(as) visitaram as escolas e apresentaram informações sobre o projeto, visando a inserção na escola de forma participativa e integrada. Todos participantes foram voluntários e tiveram explicações detalhadas sobre os objetivos da pesquisa; leram e assinaram o Termo de Consentimento Livre e Esclarecido de acordo com os procedimentos éticos indicados na Resolução 196/96 do Ministério da Saúde. Em seguida, os questionários foram aplicados e o tempo médio de resposta dos participantes ao questionário foi de uma hora e meia. Os dados foram analisados dentro dos parâmetros estatísticos previstos pelo programa SPSS, utilizando-se, nas tabelas, o total de participantes que respondeu a cada uma das questões aqui descritas. 


\section{Resultados}

Ao se levar em conta os fatores sociais e pessoais de proteção de jovens do Distrito Federal, os dados referentes às redes de apoio e aos fatores de proteção pessoal dos jovens pesquisados são apresentados a seguir. É importante salientar que os números apresentados referem-se ao total de respondentes em cada questão selecionada e que, portanto, a somatória das porcentagens não traz relação direta com o $N$ total da amostra.
A literatura mostra que o tipo e a qualidade do vínculo estabelecido dentro de cada uma das partes das redes sociais referem-se à capacidade de resistir ao comportamento de risco, podendo esta ser aumentada ou diminuída (Santana, Doninelli, \& Koller, 2004). Nesse contexto, a perspectiva familiar dos participantes foi explorada a partir de questões que visavam saber o tipo de ambiente que eles têm em casa. De um modo geral, as respostas permitiram a identificação de um caráter positivo para as vivências familiares, como mostra a Tabela 1.

Tabela 1

Família e ambiente familiar na perspectiva dos jovens

\begin{tabular}{lccc}
\hline & Discordo & $\begin{array}{c}\text { Não concordo } \\
\text { Nem discordo }\end{array}$ & Concordo \\
\hline Pais ou familiares incentivam os estudos & $4 \%$ & $9,4 \%$ & $86,6 \%$ \\
& $(\mathrm{n}=34)$ & $(\mathrm{n}=80)$ & $(\mathrm{n}=737)$ \\
Sente-se seguro com a família & $3,4 \%$ & $14,5 \%$ & $82,1 \%$ \\
Fico à vontade e m casa & $(\mathrm{n}=29$ & $(\mathrm{n}=123)$ & $(\mathrm{n}=696)$ \\
& $7 \%$ & $14,7 \%$ & $78,3 \%$ \\
Te nho privacidade & $(\mathrm{n}=59)$ & $(\mathrm{n}=125)$ & $(\mathrm{n}=664)$ \\
& $13,8 \%$ & $28,3 \%$ & $57,9 \%$ \\
O ambiente é pesado & $(\mathrm{n}=116)$ & $(\mathrm{n}=239)$ & $(\mathrm{n}=489)$ \\
Pres encio situações de alcoolismo & $71,1 \%$ & $21,8 \%$ & $7,1 \%$ \\
& $(\mathrm{n}=597)$ & $(\mathrm{n}=183)$ & $(\mathrm{n}=60)$ \\
Encontro o apoio que nece ssito & $73,5 \%$ & $11,2 \%$ & $15,3 \%$ \\
& $(\mathrm{n}=616)$ & $(\mathrm{n}=94)$ & $(\mathrm{n}=128)$ \\
Há respeito mútuo entre as pesso as & $11 \%$ & $21,3 \%$ & $67,7 \%$ \\
As pessoas dão atenção ao que eu falo & $(\mathrm{n}=93)$ & $(\mathrm{n}=179)$ & $(\mathrm{n}=569)$ \\
As pessoas se ajudam mutuamente & $9,3 \%$ & $28,4 \%$ & $62,3 \%$ \\
& $(\mathrm{n}=77)$ & $(\mathrm{n}=236)$ & $(\mathrm{n}=517)$ \\
& $10 \%$ & $32,7 \%$ & $57,3 \%$ \\
& $(\mathrm{n}=83)$ & $(\mathrm{n}=273)$ & $(\mathrm{n}=478)$ \\
& $12,1 \%$ & $34,9 \%$ & $53 \%$ \\
& $(\mathrm{n}=102)$ & $(\mathrm{n}=395)$ & $(\mathrm{n}=448)$ \\
\hline
\end{tabular}

Como mostram os dados, o envolvimento positivo da família já começa com o apoio que é dado aos estudos, afirmação que obteve a concordância de $86 \%$ dos participantes. Além de apoiar os estudos, na visão dos participantes, a família também oferece segurança $(82,1 \%)$, sendo um ambiente em que não há conflitos relevantes $(71,1 \%)$. A maioria dos participantes $(57,9 \%)$ informa ter privacidade em casa e que há respeito mútuo entre as pessoas (62,3\%). Os adolescentes entrevistados $(57,3 \%)$ afirmam que quando falam, obtêm a atenção dos familiares, e, para $53 \%$, tendem a se ajudar mutuamente. Como possibilidades de vivências estressoras, 15,3\% dos participantes relatam que vivenciam o alcoolismo no contexto familiar. Embora haja um percentual expressivo de respostas neutras a algumas dessas indagações, como mostra a Tabela 1, as respostas negativas tendem a apresentar indicadores baixos, o que contribui para a tese de que os participantes têm uma percepção predominantemente positiva do seu ambiente familiar. Estes dados favorecem a constatação de que é necessário discutir e combater o preconceito que esta população sofre, quando são identificados como marginais, desapegados à sua família e entregues aos comportamentos de risco.

Além do núcleo familiar, outro grupo importante, tanto para a proteção quanto para a constituição de identidade dos participantes é a rede de amigos. $\mathrm{O}$ questionário apresenta um conjunto de itens capazes de mapear o conforto e segurança dos participantes em relação aos amigos. A Tabela 2 apresenta os dados apresentados pelos adolescentes pesquisados sobre as relações de amizade.

A primeira constatação é de que os adolescentes investigados têm amigos. O percentual de respostas afirmativas a essa questão foi de $96,3 \%$. No entanto, considerada a importância de ter amigos para o desenvolvimento saudável, os 3,7\% de participantes que declararam não tê-los são um caso de preocupação. Os amigos têm muitas funções na vida dos adolescentes entrevistados, incluindo apoio emocional, espiritual, material, social e até apoio em tarefas escolares. Ao observar com mais detalhe a Tabela 2, 
Ta bela 2 .

Percepção dos jovens sobre os amigos e tipo de apoio pessoal e social

\begin{tabular}{|c|c|c|}
\hline & Sim & Não \\
\hline Te $\mathrm{m}$ amigos? & $\begin{array}{c}96,3 \% \\
(n=818)\end{array}$ & $\begin{array}{c}3,7 \% \\
(n=31)\end{array}$ \\
\hline Amigos devem dar apoio emocional? & $\begin{array}{c}92,8 \% \\
(n=764)\end{array}$ & $\begin{array}{c}7,2 \% \\
(n=59)\end{array}$ \\
\hline Amigos d evem dar apoio material? & $\begin{array}{c}42,1 \% \\
(n=300)\end{array}$ & $\begin{array}{c}57,9 \% \\
(n=412)\end{array}$ \\
\hline Amigos d evem dar apoio espiritual? & $\begin{array}{c}43,9 \% \\
(n=311)\end{array}$ & $\begin{array}{c}56,1 \% \\
(n=397)\end{array}$ \\
\hline Amigos d evem dar apoio nas atividades da casa e escola? & $\begin{array}{c}50,3 \% \\
(n=368)\end{array}$ & $\begin{array}{c}49,7 \% \\
(n=364)\end{array}$ \\
\hline Amigos devem dar apoio social? & $\begin{array}{c}68,7 \% \\
(n=535)\end{array}$ & $\begin{array}{c}31,3 \% \\
(n=244)\end{array}$ \\
\hline Recebe apoio so cial dos amigos? & $\begin{array}{c}56,5 \% \\
(n=419)\end{array}$ & $\begin{array}{c}43,5 \% \\
(n=322)\end{array}$ \\
\hline Pode contar com os am igos? & $\begin{array}{c}91,5 \% \\
(n=604)\end{array}$ & $\begin{array}{c}8,5 \% \\
(n=56)\end{array}$ \\
\hline Dá a poio emocional aos a migos? & $\begin{array}{c}88 \% \\
(\mathrm{n}=711)\end{array}$ & $\begin{array}{c}12 \% \\
(n=97)\end{array}$ \\
\hline Dá apoio espiritual aos amigos? & $\begin{array}{c}45,3 \% \\
(n=322)\end{array}$ & $\begin{array}{c}54,7 \% \\
(n=389)\end{array}$ \\
\hline Apoia as tarefas escolares dos amigos? & $\begin{array}{c}60,5 \% \\
(n=454)\end{array}$ & $\begin{array}{c}39,5 \% \\
(n=296)\end{array}$ \\
\hline Dá apoio social aos amigos? & $\begin{array}{c}59,7 \% \\
(n=450)\end{array}$ & $\begin{array}{c}40,3 \% \\
(n=304)\end{array}$ \\
\hline Amigos podem contar com você? & $\begin{array}{c}96,1 \% \\
(n=623)\end{array}$ & $\begin{array}{c}3,9 \% \\
(n=25)\end{array}$ \\
\hline
\end{tabular}

nos dados que se referem às diferentes funções da amizade, a que mais se destaca diz respeito ao apoio emocional. Os adolescentes $(92,8 \%)$ não só acham que amigos devem dar apoio emocional, como declararam (88\%) que oferecem este tipo de apoio aos amigos. Outros itens citados foram: apoio social, apoio nas tarefas escolares e a disposição para ajudar os amigos, presente no reconhecimento, por parte de $96,1 \%$ dos participantes, de que os amigos podem contar com eles. Ainda em relação às amizades, os jovens informam que a maior incidência de amigos $(89,8 \%)$ é da escola. Mas muitos têm amigos no bairro $(66,5 \%)$, na rua em que moram (66,5\%) e 20,4\% têm amigos virtuais pela internet. A maioria (80,1\%) tem alguém especial a quem considera o seu melhor amigo, que tende a ser do mesmo sexo do participante em $65,5 \%$ dos casos.

Outro importante fator de proteção e promotor de resiliência no contexto de vida de adolescentes em situação de risco psicossocial, enfatizado pela literatura, refere-se ao tipo de envolvimento que eles têm com a escola. Na pesquisa foram endereçadas questões relativas tanto ao lugar da escola na vida dos participantes - no presente e no futuro - quanto às relações com o ambiente, com outras pessoas e com a construção de laços de confiança. A Tabela 3 mostra os dados obtidos.
Como evidenciado na Tabela 3, as percepções sobre o papel da escola e dos estudos na vida dos estudantes são positivas. Os jovens acham que os estudos são muito importantes atualmente (90,5\%), e também para o futuro $(84,1 \%)$. Relacionada a esta percepção de importância, estão tanto o forte desejo de fazer faculdade $(84,1 \%)$, quanto o reconhecimento de que para alcançar isto é necessário muito esforço pessoal (84,1\%). Os itens do questionário relativos à importância dos estudos para o futuro, ao desejo de fazer faculdade e à necessidade de muito estudo para alcançar este objetivo obtiveram rigorosamente o mesmo percentual de respostas concordantes $(84,1 \%)$. Além de acreditarem em seu futuro vinculado à escola, os participantes parecem rejeitar a idéia de que quem frequenta escola pública está em desvantagem no que diz respeito a projetos futuros envolvendo o ensinor superior. A afirmação de que só quem frequenta a escola particular entra para a universidade obteve a discordância de 73,6\% dos participantes.

Dada a importância fundamental da escola, tanto no contexto atual da vida dos participantes, como no que diz respeito ao seu projeto futuro, buscou-se saber que tipo de relacionamento os participantes têm com o ambiente escolar. Os dados estão explicitados na Tabela 4. 
Ta bela 3

O papel da escola e dos estudos na vida dos jovens

\begin{tabular}{lccc}
\hline & Discordo & $\begin{array}{c}\text { Não concordo } \\
\text { Nem discordo }\end{array}$ & Concordo \\
\hline Meus es tudos são importantes hoje. & $3,3 \%$ & $6,2 \%$ & $90,5 \%$ \\
& $(\mathrm{n}=28)$ & $(\mathrm{n}=53)$ & $(\mathrm{n}=774)$ \\
Meus es tudos são importantes para o futuro. & $2,3 \%$ & $3,7 \%$ & $84,1 \%$ \\
& $(\mathrm{n}=20)$ & $(\mathrm{n}=32)$ & $(\mathrm{n}=709)$ \\
Desejo m uito fazer faculdade. & $4,5 \%$ & $11,4 \%$ & $84,1 \%$ \\
& $(\mathrm{n}=38)$ & $(\mathrm{n}=96)$ & $(\mathrm{n}=709)$ \\
Preciso estudar muito para alcançar meu sonho. & $3,3 \%$ & $6,1 \%$ & $84,1 \%$ \\
& $(\mathrm{n}=28)$ & $(\mathrm{n}=52)$ & $(\mathrm{n}=709)$ \\
Só quem frequenta a escola particular entra para a universidade. & $73,6 \%$ & $16,5 \%$ & $9,9 \%$ \\
& $(\mathrm{n}=726)$ & $(\mathrm{n}=140)$ & $(\mathrm{n}=84)$ \\
\hline
\end{tabular}

Tabela 4

Percepção dos jovens sobre os professor es e o contexto escolar

\begin{tabular}{lccc}
\hline & Discordo & $\begin{array}{c}\text { Não concordo } \\
\text { nem discordo }\end{array}$ & Concordo \\
\hline Posso contar com professores e equipe escolar. & $\begin{array}{c}18,9 \% \\
(\mathrm{n}=160)\end{array}$ & $\begin{array}{c}40,9 \% \\
(\mathrm{n}=346)\end{array}$ & $\begin{array}{c}40,1 \% \\
(\mathrm{n}=339)\end{array}$ \\
Confio na maioria dos professo res. & $23,6 \%$ & $39,5 \%$ & $37 \%$ \\
& $(\mathrm{n}=197)$ & $(\mathrm{n}=330)$ & $(\mathrm{n}=309)$ \\
Posso contar com a ajuda dos amigos da escola. & $13,1 \%$ & $36,7 \%$ & $50,2 \%$ \\
& $(\mathrm{n}=111)$ & $(\mathrm{n}=311)$ & $(\mathrm{n}=425)$ \\
Gosto da maioria dos amigos da escola. & $6,7 \%$ & $16,1 \%$ & $77,2 \%$ \\
& $(\mathrm{n}=57)$ & $(\mathrm{n}=137)$ & $(\mathrm{n}=656)$ \\
Confio nos amigos d a escola. & $19,7 \%$ & $41,1 \%$ & $39 \%$ \\
& $(\mathrm{n}=166)$ & $(\mathrm{n}=346)$ & $(\mathrm{n}=328)$ \\
Gosto da maioria dos professores & 15,6 & $24,7 \%$ & $59,6 \%$ \\
& $(\mathrm{n}=133)$ & $(\mathrm{n}=210)$ & $(\mathrm{n}=507)$ \\
Sinto-me bem na escola & $7,6 \%$ & $33,7 \%$ & $58,7 \%$ \\
& $(\mathrm{n}=65)$ & $(\mathrm{n}=288)$ & $(\mathrm{n}=501)$ \\
\hline
\end{tabular}

Pode-se perceber que, no posicionamento dos participantes quanto a aspectos específicos da escola (professores e equipe escolar), apenas $40,1 \%$ considera que pode contar com professores e equipe escolar. Este indicador encontra correspondência com a confiança nos professores, manifesta por somente $37 \%$ dos participantes. No entanto, se a declaração de confiança nos professores é modesta, os laços afetivos mostram-se mais generosos, já que 59,6\% dos participantes declaram gostar dos seus professores, embora não confiem tanto neles. No que diz respeito aos amigos da escola, as percepções são melhores. A maioria dos participantes $(77,2 \%)$ gosta e $50,2 \%$ informa que pode contar com os colegas, embora somente 39\% declarem que podem confiar neles. Esses dados, observados de forma conjunta, sugerem uma percepção geral positiva do ambiente escolar, que pode ser corroborada pelo fato de a maioria dos participantes $(58,7 \%)$ se sentir bem na escola. Porém, os dados com relação à percepção dos adolescentes sobre confiança e apoio dos professores indicam a necessidade de estudos específicos sobre esta temática, uma vez que a relação professoraluno é fundamental nos processos de aprendizagem e, segundo os dados aqui aprensentados, esta encontra-se comprometida e com baixa efetividade na vida destes adolescentes.

No que se refere aos fatores pessoais, como eixo fundamental de proteção, pode-se destacar elementos que compõem essas estratégias como: a espiritualidade e religiosidade, a autoestima, a auto-eficácia e o bem estar. Destaca-se o modo como esses jovens investem na sua espiritualidade e como esta espiritualidade contribui para sua auto-estima e, portanto, para sua resiliência. Esses elementos, identificados como fatores de proteção, se caracterizam como um suporte pessoal para o jovem diante da exposição aos fatores de risco. No grupo dos participantes, a busca da espiritualidade, ou até mesmo da religião, revelou-se como um importante foco de investimento pessoal. A Tabela 5 apresenta os dados obtidos. 
Ta bela 5

Religião e espiritualidade na perspectiva dos jovens

\begin{tabular}{|c|c|c|c|c|c|}
\hline & $\begin{array}{c}\text { Nem um } \\
\text { pouco }\end{array}$ & Pouco & $\begin{array}{l}\text { Nem muito } \\
\text { nem pouco }\end{array}$ & Bastante & Muito \\
\hline A religião tem sido importante para vida & $\begin{array}{l}11,7 \% \\
(n=97)\end{array}$ & $\begin{array}{c}9,2 \% \\
(n=76)\end{array}$ & $\begin{array}{c}17,4 \% \\
(n=144)\end{array}$ & $\begin{array}{c}25,5 \% \\
(n=211)\end{array}$ & $\begin{array}{c}36,1 \% \\
(n=298)\end{array}$ \\
\hline Freqüenta encontros religiosos & $\begin{array}{c}13,2 \% \\
(n=109)\end{array}$ & $\begin{array}{c}23,6 \% \\
(n=194)\end{array}$ & $\begin{array}{c}21,9 \% \\
(n=180)\end{array}$ & $\begin{array}{c}18,5 \% \\
(n=152)\end{array}$ & $\begin{array}{l}22,8 \% \\
(n 188)\end{array}$ \\
\hline Costuma ler escrituras sagrada ou fazer orações & $\begin{array}{l}11,9 \% \\
(n=98)\end{array}$ & $\begin{array}{c}25,3 \% \\
(n=208)\end{array}$ & $\begin{array}{c}23,2 \% \\
(n=191)\end{array}$ & $\begin{array}{c}20,8 \% \\
(n=171)\end{array}$ & $\begin{array}{c}18,8 \% \\
(n=155)\end{array}$ \\
\hline Costuma agradecer a Deus & $\begin{array}{c}3,8 \% \\
(n=31)\end{array}$ & $\begin{array}{c}12,7 \% \\
(\mathrm{n}=105)\end{array}$ & $\begin{array}{c}15,2 \% \\
(n=125)\end{array}$ & $\begin{array}{c}28,2 \% \\
(n=233)\end{array}$ & $\begin{array}{c}40,1 \% \\
(n=331)\end{array}$ \\
\hline Pede ajuda a Deus para resolver os problemas & $\begin{array}{c}4,0 \% \\
(n=33)\end{array}$ & $\begin{array}{c}7,8 \% \\
(n=64)\end{array}$ & $\begin{array}{l}10,9 \% \\
(n=90)\end{array}$ & $\begin{array}{c}31,3 \% \\
(n=258)\end{array}$ & $\begin{array}{c}46,0 \% \\
(n=379)\end{array}$ \\
\hline Lê escrituras ou ora quando em dificuldade & $\begin{array}{c}8,9 \% \\
(n=74)\end{array}$ & $\begin{array}{c}14,3 \% \\
(n=119)\end{array}$ & $\begin{array}{c}19,1 \% \\
(n=159)\end{array}$ & $\begin{array}{c}23,1 \% \\
(n=192)\end{array}$ & $\begin{array}{c}34,5 \% \\
(n=287)\end{array}$ \\
\hline $\begin{array}{l}\text { Busca ajuda de sua instituição religiosa quando } \\
\text { em dificuldade }\end{array}$ & $\begin{array}{c}30,9 \% \\
(n=257)\end{array}$ & $\begin{array}{c}21,6 \% \\
(n=180)\end{array}$ & $\begin{array}{c}20,7 \% \\
(n=172)\end{array}$ & $\begin{array}{l}10,9 \% \\
(n=91)\end{array}$ & $\begin{array}{l}15,9 \% \\
(\mathrm{n}=132)\end{array}$ \\
\hline
\end{tabular}

Como se pode verificar, $62 \%$ dos jovens considera a religião como sendo bastante ou muito importante e $38,2 \%$ referem-se a ela como tendo pouca ou nenhuma importância. Porém, apesar do valor atribuído à religião, somente $41,3 \%$ freqüentam (bastante e muito) encontros religiosos e 38,6\% costumam ler (bastante e muito) as escrituras sagradas. A relação com a espiritualidade no sentido da crença em interseções favoráveis, contudo, parece muito fortalecida, pois $77 \%$ dos jovens costumam pedir (bastante e muita) ajuda para resolver seus problemas e $68,3 \%$ costumam agradecer (bastante e muito) a Deus. Os dados evidenciam o movimento destes jovens na direção da crença e estruturação de valores com base em preceitos religiosos e espirituais, sendo que esta dimensão é apontada na literatura como efetiva proteção e promotora de resiliência (Koenig, McCullough, \& Larson, 2001; Whitehead, Wilcox, \& Rostosky, 2001). Porém, é importante salientar que esta é uma busca, um movimento individual, pois, a maioria dos jovens pesquisados não costuma freqüentar instituições religiosas.

$\mathrm{Na}$ identificação de outro aspecto relevante enquanto característica pessoal protetiva, nas questões relativas à auto-estima os jovens demonstram que a possuem de forma considerada elevada. A Tabela 6 apresenta os dados relativos a este aspecto.

Os dados mostram que $80,5 \%$ dos jovens declaram sentiremse pessoas de valor, $72,1 \%$ acham que tem boas qualidades e $57,8 \%$ se consideram criativos. Esses dados, considerados positivos e sustentadores de boas estratégias de proteção, não obscurecem, contudo, a existência de sentimentos negativos com relação a si próprios. Surgem em número expressivo os pensamentos sobre não prestarem para nada $(28,6 \%)$, as manifestações ocasionais de inutilidade $(24,8 \%)$, ou os sentimentos de fracasso $(18,1 \%)$. No seu conjunto, os dados trazem o impacto das percepções subjetivas destes jovens, assinalando a convivência entre aspectos considerados positivos

Tabela 6

Auto-estima dos jovens em relação às qualidades valor pessoal e criativiadade

\begin{tabular}{lccc}
\hline & Discordo & $\begin{array}{c}\text { Não concordo } \\
\text { Nem discordo }\end{array}$ & Concordo \\
\hline Sente que é uma pessoa de valor & $3,1 \%$ & $16,4 \%$ & $80,5 \%$ \\
& $(\mathrm{n}=26)$ & $(\mathrm{n}=138)$ & $(\mathrm{n}=678)$ \\
Considera-se criativo(a) & $13,4 \%$ & $28,8 \%$ & $57,8 \%$ \\
& $(\mathrm{n}=107)$ & $(\mathrm{n}=2294)$ & $(\mathrm{n}=460)$ \\
Às vezes pensa que não presta pra nada & $41,6 \%$ & $29,8 \%$ & $28,6 \%$ \\
& $(\mathrm{n}=333)$ & $(\mathrm{n}=238)$ & $(\mathrm{n}=229)$ \\
Sente-se um fracasso & $62 \%$ & $19,9 \%$ & $18,1 \%$ \\
& $(\mathrm{n}=492)$ & $(\mathrm{n}=158)$ & $(\mathrm{n}=144)$ \\
Ás vezes sente-se inútil & $46,5 \%$ & $28,7 \%$ & $24,8 \%$ \\
& $(\mathrm{n}=368)$ & $(\mathrm{n}=227)$ & $(\mathrm{n}=196)$ \\
Acha que tem muitas boas qualidades & $7,5 \%$ & $20,4 \%$ & $72,1 \%$ \\
& $(\mathrm{n}=60)$ & $(\mathrm{n}=163)$ & $(\mathrm{n}=576)$ \\
\hline
\end{tabular}


e negativos de forma harmônica e esperada. Ao se considerar a perspectiva contextual da adolescência na atualidade, que se caracteriza pela interação pessoa-ambiente e assinala nas vivências de situação de risco psicossocial as dinâmicas entre risco e proteção, os dados obtidos permitem a visualização de uma juventude comprometida consigo mesma e consciente de limites e frustrações importantes para o próprio amadurecimento e para a busca de alternativas para seu cotidiano.

\section{Discussão}

Os dados encontrados neste estudo, relacionados aos fatores de proteção, demonstraram que estes adolescentes e jovens possuem bons elementos para favorecer os seus processos de resiliência global (social, emocional e acadêmica), uma vez que mostram capacidade em manter, mesmo em situações adversas, a confiança em si mesmos e na rede composta por família e amigos. Segundo Branden (1998), estes aspectos representam certa coesão, estabilidade, respeito, apoio e suporte nos núcleos familiares ou na família mais ampla, além do grupo de amigos, o que fortifica as possibilidades de elaboração e efetivação de boas estratégias de adaptação saudável aos eventos estressores. Estudos recentes sugerem que os adolescentes são profundamente influenciados pelos pais, com a mesma freqüência com que o são pelos companheiros e, ainda, sugerem a multiplicidade e a diversidade que caracterizam seus modelos de comportamento e sistema de valores. Os dados do estudo aqui apresentados corroboram a literatura, além de identificarem estas redes de mútua influência como protetivas para o desenvolvimento sócioemocional dos jovens estudados.

Quanto aos fatores relacionados ao apoio do meio ambiente amplo, destaca-se o ambiente escolar, pois a maior parte dos respondentes enfatizou a escola como tendo uma qualidade boa ou muito boa. Associada a este dado tem-se a valorização dos estudos em suas vidas e o fato dos relacionamentos no âmbito escolar, ou até fora dele, estarem contribuindo para sua resiliência. Estes dados são relevantes, pois, apontam para a confiança que os jovens depositam no seu desempenho acadêmico e no suporte advindo da construção formal do conhecimento, sendo fundamentais para sensibilizar as autoridades competentes na efetivação de Políticas Públicas adequadas e contextuais para esta população (De Antoni \& Koller, 2004; Werner, 1993). O fato de o grupo de jovens participantes da pesquisa cursar o ensino médio gerou, possivelmente, esse fator de permanência em uma escola e é sentido pelos jovens como característica protetiva, podendo contribuir para redução de exposição ao risco psicossocial. Entretanto, é importante valorizar a figura do professor enquanto adulto de referência e apresentar, mais uma vez, que seu papel na vida dos adolescentes pesquisados encontra-se comprometido com os fatores de risco, mais do que com os de proteção.

O principal fator de risco para estes jovens, a princípio, é o baixo nível sócio-econômico com o qual interagem, evidenciando a possibilidade de problemas de manutenção e sobrevivência na família, uso/tráfico de drogas e, em alguns casos, vivências de violência. Porém, para os jovens pesquisados, a presença das redes de proteção (família, escola e amigos) contribui para o aumento das vivências resilientes, favorecendo a construção de estratégias protetivas e socialmente ampliadas.

No que se refere aos fatores pessoais, a religiosidade e a espiritualidade parecem também atuar como elementos protetivos, quando os jovens qualificam esses aspectos, além de uma possível crença em "Deus", incluindo uma necessidade de bem estar e de crescimento. A religiosidade foi destacada por Bucher (1988) como um fator preventivo primário, na medida em que impediria o início do uso de drogas. Nesse sentido, os jovens aqui pesquisados encontram um conjunto de fatores sociais e psíquicos que atuam como elementos protetivos em relação aos fatores de risco.

Vale a pena destacar a auto-estima como um importante fator de proteção individual e algumas questões respondidas indicaram a construção de um alto juízo de valor sobre si mesmo. A auto-estima é um conceito complexo e está relacionado à saúde mental ou bem estar psicológico e sua carência se relaciona com certos fenômenos mentais negativos como depressão e suicídio (Gobitta \& Guzzo, 2002). É recorrente, na literatura psicológica, relacionar variáveis agindo diretamente na auto-estima como: a situação econômica familiar, o nível socioeconômico e a localização geográfica de habitação, o que poderia evidenciar, na amostra estudada, possibilidades de baixa auto-estima, uma vez que viviam em regiões bastante desassistidas. Contudo, Coopersmith (1967) concluiu que não existem correlações significantes entre estes fatores. Em contrapartida, constatou como significativo para a formação do eu o relacionamento entre pessoas significativas na vida que compartilham o mesmo contexto. Considera-se, portanto, que a auto-estima enquanto um elemento protetivo é também tributário de outros elementos, como os modos como estes jovens a construíram, a aceitação de seus pensamentos, o fato de estarem inseridos num contexto com limites claramente definidos e conviverem com adultos que não usam de autoritarismo e violência para controlá-los (Gobitta \& Guzzo, 2002).

\section{Considerações finais}

Ao se considerar os fatores de proteção indicados neste estudo, é importante destacar que eles estão integrados e ativos: a espiritualidade, a consolidação da auto-estima, a presença positiva da família e dos amigos. Assim, os dados apresentados neste estudo mostram que é necessário, como um suporte mediador das situações de risco às quais potencialmente esses jovens estão submetidos, um conjunto de fatores protetores, como auto-estima, boas relações pessoais com amigos, professores, familiares, vizinhança, além da presença do apoio emocional e social recebidos. Assim, uma rede de sustentação para jovens que estejam em um ambiente considerado de risco pode, efetivamente, contribuir para que sua resiliência e a efetiva estruturação de recursos individuais e sociais para o enfrentamento das adversidades. Esses fatores contribuem para resolução dos problemas e para a manutenção do desenvolvimento saudável. Neste sentido, apresenta-se a necessidade de estudos que focalizem as questões de risco psicossocial na dimensão interativa entre risco e proteção e, sobretudo, na identificação e valorização dos aspectos saudáveis 
do desenvolvimento. Esta necessidade apontada também por outros autores (Rutter, 1987; Seligman \& Csikszentmihalyi, 2000), fortifica-se não só na perspectiva dos fatores de proteção como integrantes na realização dos processos resilientes, mas, também, como aspectos fundamentais na construção do desenvolvimento humano através de movimentos saudáveis e de evidente crescimento nas dimensões consideradas positivas.

Como apreciações finais, faz-se necessário considerar que a temática aqui apresentada enfatiza a importância de estudos futuros sobre a questão da adolescência e da juventude e do risco e proteção em seu desenvolvimento. Tanto com relação aos fatores de risco, como aos de proteção identificados e descritos neste estudo, há espaço para o aprofundamento dos dados, buscando-se, através de modelos de pesquisa multi-instrumentais e analíticos, as características dos processos particulares, das vivências subjetivas que diferenciam e qualificam as experiências destes adolescentes. A família, a escola e a rede social são, como indicado na literatura, possíveis de uma valorização maior ou menor na perspectiva da promoção da resiliência. Portanto, é fundamental pesquisar estes ambientes em suas particularidades e combinações e, ainda, valorizar a criação e aplicação de instrumentos distintos de questionários, no sentido de criar bancos de dados funcionais e efetivos para a criação e implementação de Políticas Públicas e projetos de intervenção junto à população adolescente. Por fim, cabe destacar que, nesse estudo, os conceitos de adolescência e juventude foram trabalhados de forma ampla, assim como a coleta de dados não privilegiou diferenciações nos seus processos de desenvolvimento, uma vez que a freqüência em determinadas séries escolares é que motivou a composição da amostra. Sugere-se que outros estudos na área abordem essa diferenciação, trazendo os critérios dos processos desenvolvimentais como aspectos fundantes das coletas e discussões de dados, fortificando as dimensões apresentadas no Estatuto da Criança e do Adolescente e pela Organização Mundial de Saúde.

\section{Referências}

Branden, N. (1998). Auto-estima: como aprender a gostar de si mesmo. São Paulo: Saraiva.

Bronfenbrenner, U. (1979/1996). A ecologia do desenvolvimento humano: experimentos naturais e planejados. Porto Alegre: Artes Médicas.

Bronfenbrenner, U. (1989). Ecological systems theory. Annals of Child Development, 6, 187-249.

Bucher, R. (1988). A abordagem preventiva. In R. Bucher (Org.), As drogas e a vida: uma abordagem biopsicossocial (pp. 55-67). São Paulo: EPU.

Coopersmith, S. (1967). The antecedents of self-esteem. São Francisco: Freeman.

De Antoni, C. \& Koller, S. H. (2004). A pesquisa psicológica sobre violência no microssistema familiar. In S. H. Koller (Org.), Ecologia do desenvolvimento humano: pesquisa e intervenção no Brasil (pp. 311-336). São Paulo: Casa do Psicólogo.

Gobitta, M., \& Guzzo, R. S. L. (2002). Estudo inicial do inventário de Auto-Estima (SEI): Forma A. Psicologia: Reflexão e Crítica, 15(1), 143-150.

Grotberg, E. (1995). A guide to promoting resilience in children: strengthening the human spirit. The Hague: The Bernard van Leer Foundation.

Junqueira, M. P., \& Deslandes, S. F. (2003). Resiliência e maus tratos à criança. Caderno de Saúde Pública, 19(1), 227-335.

Koenig, H. G., McCullough, M. E., \& Larson, D. B. (2001). Handbook of religion and health. Oxford: Oxford University Press.

Koller, S. H. (1999). Resiliência e vulnerabilidade em crianças que trabalham e vivem na rua. Educar Em Revista, 15, 67-71.

Koller, S. H. (2004). Conversando com Bronfenbrenner. In S. H. Koller (Org.), Ecologia do desenvolvimento humano: pesquisa e intervenção no Brasil (pp. 47-61). São Paulo: Casa do Psicólogo.

Koller, S. H., \& Lisboa, C. S. de M. (2007). Brazilian approaches to understanding and building resilience in at-risk populations. Child and Adolescent Psychiatric Clinics of North America, 16, 341-356.

Luthar, S. (1993). Annotation: methodological and conceptual issues in research on childhood resilience. Journal of Child Psychology and Psychiatric, 34, 441-453.

Morais, N. A., \& Koller, S. H. (2004). Abordagem ecológica do desenvolvimento humano, Psicologia Positiva e resiliência: ênfase na saúde. In S. H. Koller (Org.), A ecologia do desenvolvimento humano: pesquisa e intervenção no Brasil (pp. 91-108). São Paulo: Casa do Psicólogo.

Narvaz, M. G., \& Koller, S. H. (2004). O modelo bio-ecológico do desenvolvimento humano. In S. H. Koller (Org.), A ecologia do desenvolvimento humano: pesquisa e intervenção no Brasil (pp.51-66). São Paulo: Casa do Psicólogo.

Pesce, R., Assis, S., Santos, N., \& Oliveira, N. (2005). Risco e proteção: em busca de um equilíbrio promotor de resiliência. Psicologia: Teoria e Pesquisa, 20(2), 135-143.

Pinheiro, D. P. N. (2004). A resiliência em discussão. Psicologia em Estudo, $9(1), 67-75$.

Rutter, M. (1987). Psychosocial resilience and protective mechanisms. American Orthopsychiatric Association, 57(3), 316-331.

Rutter, M. (1993). Resilience: some conceptual considerations. Journal of Adolescent Health, 14, 626-631.

Santana, J. P., Doninelli, T. M., \& Koller, S. H. (2004). Instituições de atendimento a crianças e adolescentes em situação de rua. Psicologia \& Sociedade, 16(2), 59-70.

Seligman, M. E. P., \& Csikszentmihalyi, M. (2000). Positive Psychology: An introduction. American Psychologist, 55(1), 5-14.

Werner, E., \& Smith, R. S. (1992). Overcoming the odds: high-risk children from birth to adulthood. Ithaca/London: Cornell University Press.

Werner, E. E. (1993). Risk, resilience and recovery: perspectives from the Kauai longitudinal study. Development and Psychopathology, 5, 503-515.

Whitehead, B. D., Wilcox, B. L., \& Rostosky, S. S. (2001). Keeping the faith: the role of religion and faith communities in preventing teen pregnancy. Washington, DC: National Campaign to Prevent Teen Pregnancy.

Yunes, M. A. M. (2003). Psicologia positiva e resiliência: o foco no indivíduo e na família. Psicologia em Estudo, 8, 75-84.

Yunes, M. A. M., \& Szymansky, H. (2001). Resiliência: noção, conceitos afins e considerações críticas. In J. Tavares (Org.), Resiliência e educação (pp. 13-42). São Paulo: Cortez. 
Deise Matos do Amparo, doutora em Psicologia pela Universidade de Brasília, é professora no Programa de Pós Graduação em Psicologia da Universidade Católica de Brasília, na área de Psicopatologia e Testes Projetivos. Endereço para correspondência: Universidade Católica de Brasília - Campus Avançado Asa Norte; Programa de Pós-Graduação em Psicologia; SGAN 916 Norte Avenida W5; Brasília, DF; CEP: 70790-160. Tel.: (61) 3448-7000. E-mail: deise@ucb.br

Afonso Celso Tanus Galvão, doutor em Psicologia Educacional pela University of Reading (Inglaterra), é coordenador do Programa de Pós-Graduação em Educação da Universidade Católica de Brasília e professor no Programa de Pós-Graduação em Psicologia, na mesma universidade. E-mail: agalvao@ucb.br

Paola Biasoli Alves, doutora em Psicologia do Desenvolvimento pela Universidade Federal do Rio Grande do Sul, é professora no Curso de Psicologia da Universidade Federal do Mato Grosso. E-mail: paolabia@ yahoo.com

Katia Tarouquella Brasil, doutora em Psicologia Clínica e Cultura pela Universidade de Brasília, é professora no Programa de Pós-Graduação em Educação da Universidade Católica de Brasília. E-mail: katia@ucb.br Carmen Jansen Cardenas, doutora em Psicologia pela Universidade de Brasília, é professora no Programa de Pós-Graduação em Gerontologia da Universidade Católica de Brasília. E-mail: ccardena@ucb.br Silvia Helena Koller, doutora em Educação pela Pontifícia Universidade Católica do Rio Grande do Sul, é professora no Programa de Pós-Graduação em Psicologia do Desenvolvimento da Universidade Federal do Rio Grande do Sul e coordenadora do Centro de Estudos Psicológicos sobre Meninos e Meninas de Rua (CEP-RUA/UFRGS). E-mail: silvia.koller@pq.cnpq.br 